
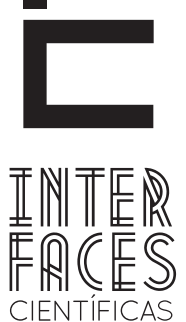

DIREITO

\title{
DESENVOLVIMENTO SOCIOECONOMICO E A CIDADE ILEGAL NA REGIÃO METROPOLITANA DE SÃO PAULO: A QUESTÃO DA MORADIA
}

\author{
Leticia Galan Garducci ${ }^{1}$
}

\section{RESUMO}

Este artigo busca compreender a questão da moradia ilegal e irregular na região metropolitana de São Paulo e de que maneira a concessão ou regularização da propriedade contribui para solucionar o problema da má qualidade na habitação da população de baixa renda desta região. Para tanto, parte da análise do desenvolvimento socioeconômico no país para traçar o processo de urbanização da Metrópole de São Paulo e verificar como se desenvolveu o cenário de ocupação ilegal e propriedade irregular nesta região. Após, examina os pontos do debate acerca da regularização da propriedade como solução para a questão da moradia precária, com o escopo de compreender se a concessão ou regularização do título de propriedade contribui para solucionar a precariedade na habitação, tão recorrente no espaço urbano.

\section{PALAVRAS-CHAVE}

Cidade ilegal. Desenvolvimento socioeconômico. Moradia informal. São Paulo. Urbanização.

\section{ABSTRACT}

This article seeks to understand the question of illegal and irregular housing in metropolitan São Paulo and how the grant or settlement of property contributes to solve the problem of poor quality housing in the low-income population of this region. For this, part of the analysis of the socio-economic development in the country to trace the process of urbanization of the metropolis of Sao Paulo and check how it developed the scenario of illegal occupation and property irregular in this region. After examining the points of the debate on property regulation as a solution to the issue of poor housing, to understand whether the granting or regularization of title resolves the precarious housing, so common in the urban space.

\section{KEYWORDS}

Illegal City. Socioeconomic Development. Informal Housing. Sao Paulo. Urbanization. 


\section{RESUMEN}

En este artículo se busca entender el tema de la vivienda ilegal e irregular en el área metropolitana de São Paulo y la forma en que la concesión o liquidación de los bienes contribuye a resolver el problema de la mala calidad de la vivienda en la población de bajos ingresos de la región. Por lo tanto, el análisis del desarrollo socio-económico en el país para rastrear el proceso de urbanización de la metrópolis de São Paulo y ver cómo se desarrolló el escenario de la ocupación ilegal e irregular del inmueble en esta región. Tras analizar los elementos del debate sobre la regulación de la propiedad como una solución a la cuestión de la precariedad de la vivienda, con el objetivo de comprender si la concesión o la regularización de ayuda para resolver la precariedad de la vivienda, por lo recurrente en el espacio urbano.

\section{PALABRAS CLAVE}

Ciudad Ilegal. El Desarrollo Socioeconómico. Vivienda Informal. São Paulo. Urbanización.

\section{INTRODUÇãO}

As grandes metrópoles brasileiras são marcadas pelo dualismo da "cidade legal" e "cidade ilegal": é visível nas regiões metropolitanas a segregação socioespacial, em que a população, por vezes, se divide entre o centro rico e a periferia pobre, como que em universos distintos. Em outros casos, porém, convivem em um mesmo espaço, ainda que não no mesmo universo de possibilidades. A cidade ilegal é composta por habitações precárias e irregulares, e, comparada aos bairros de classe média e alta da cidade legal, evidencia-se os contrastes provocados pela má distribuição de renda que assola o país.

Este artigo tem por escopo compreender a questão da moradia ilegal e irregular na região metropolitana de São Paulo e verificar de que maneira a concessão ou regularização da propriedade contribui para solucionar o problema da precariedade na habitação.
Para tanto, se buscará traçar os processos constitutivos da formação do espaço urbano na região metropolitana de São Paulo, verificando-se as características socioeconômicas que impulsionaram essa urbanização e a formação do que se convencionou chamar, na literatura especializada, por "cidade ilegal” - ou seja, o espaço tomado pela ocupação ilegal e/ou propriedade irregular.

Ao final, se examinará a discussão acerca da regularização da propriedade como solução para a questão da moradia precária. Com isto, pretende-se compreender se a concessão ou regularização do título de propriedade contribui para solucionar o problema da precariedade na habitação, tão recorrente nas grandes cidades. 


\section{DESENVOLVIMENTO SOCIOECONÔMICO, PROCESSO DE URBANIZAÇ̃̃O E A CONSTRUÇ̄̃O DA MORA- DIA INFORMAL NA METRÓPOLE DE SÃO PAULO}

O processo de urbanização no Brasil só avançou a partir da industrialização do País, especialmente a partir da segunda metade do século XX - quando a população deixou de ser predominantemente rural (BRITO, 2006, p. 221). Assim, na virada do século XIX para o século XX, em face da estrutura agrária e exportadora que ainda caracterizava a economia nacional, a urbanização progrediu de forma lenta ${ }^{1}$, embora este processo já ocorresse de forma mais acentuada no sudeste brasileiro.

Assim, já no início do século XX, começa a se esboçar o processo de industrialização em São Paulo, momento em que surgem as vilas operárias, especialmente na região Brás-Bresser. A grande maioria das vilas foi construída por empreiteiros, o que se explica porque "o processo de acumulação do capital necessitava, pela escassez de mão-de-obra qualificada, garantir sua presença preferencialmente perto das unidades produtivas" (PASTERNAK, 2008, p. 112-113).

Com a crise econômica mundial deflagrada na década de 1930, os setores exportadores no Brasil se voltaram para o mercado nacional. Isto deu impulso a um processo de substituição de importações pela indústria nacional, que acelerou a urbanização do País: motivados por melhores condições de trabalho, se iniciou uma migração em massa de moradores da zona rural para a zona urbana.

10 que explica o processo lento de urbanização até a década de 1930 é a situação de "economia colonial" em que ainda vivia o País, em que a deterioração dos meios de troca era responsável pelo crescimento lento do mercado interno e concentração de renda do período (PAULANI, 2001, p. 139-156). Este cenário impedia o surgimento de uma indústria nacional, que por sua vez impulsionaria o processo de construção das cidades.
Isto implicou em um aumento da força de trabalho no espaço urbano, o que fez com que a construção de novas vilas para a moradia dos operários fosse deixada de lado pelos industriais e empreendedores. Estes, em função da oferta excedente de mão-de-obra, deixaram de se preocupar com a instalação dos trabalhadores perto das unidades produtivas e com suas condições materiais de reprodução. Em face disto, os trabalhadores, em face dos baixos salários que recebiam, passaram a ocupar cortiços nas regiões centrais da cidade (PASTERNAK, 2008, p. 112-113).

Vale destacar que a instalação na própria região central da cidade foi, na verdade, uma necessidade. Era preciso a proximidade com o local de trabalho, já que "os gastos com transporte em bondes, se as distâncias fossem grandes, seriam elevados e assim incompatíveis com a compressão salarial da época" (PASTERNAK, 2008, p. 112-113). Apenas a opção do governo pelo transporte rodoviário na década de 30 fez com que a população pobre começasse a ocupar os limites periféricos das cidades.

A do deslocamento para a região periférica, essa população passou a sofrer, também, com a segregação urbana: seja pelo desgaste do deslocamento diário casa-trabalho-casa, devido às grandes distâncias do local de trabalho localizado na região central da cidade; pelos altos custos da locomoção até a região central ou, ainda, pela falta de acesso aos serviços básicos oferecidos na cidade - serviços de água, esgoto, saúde, lazer, etc. -, que inexistiam nas regiões periféricas.

Além disto, a periferização a partir de 30 representou, também, o início da "cidade ilegal". As propriedades que as populações passaram a ocupar nas 
regiões periféricas foram loteadas ilegalmente ou irregularmente - ou seja, sem cumprir as exigências de assentamento da legislação municipal -, sendo que a maioria das casas desses loteamentos era autoconstruída, e se tratavam de habitações precárias (BÓGUS, 1998, p. 49; TORRES et al, 2003, p. 97-128; PASTERNAK, 2008). Ademais, desde este período já existiam na metrópole de São Paulo além de loteamentos sem licença, registros e alvarás fornecidos pela prefeitura que apresentavam problemas na titulação da propriedade (GROSTEIN, 2001, p. 15).

Assim, o surgimento desta "cidade ilegal" se relaciona com a renda da população pobre, impossibilitada de permanecer nas regiões centrais da cidade em face do alto custo imobiliário. Esta segregação também tem raízes na própria legislação da época, descolada da realidade social:

Historicamente, a legislação urbanística estabeleceu padrões de construção que não atendiam à realidade das classes trabalhadoras e acabou por fazer clara distinção para o acesso à terra entre as classes sociais existentes. Aqueles que conseguiam se adequar às imposições urbanísticas do Poder Público, o que demandava dinheiro, constituíam os habitantes da cidade legal. Já aqueles outros que não podiam fazê-lo eram empurrados para a periferia, para onde não havia padrões urbanísticos estabelecidos, ou violavam os vigentes nas tais áreas privilegiadas (DOURADO, 2003, p. 471-472).

Ou seja, o poder econômico, combinado com uma legislação para poucos é que vai conformar o processo de formação das cidades. Assim, desde o início do processo de urbanização, verifica-se que a desigualdade de renda promove o acesso desigual à cidade, inclusive sob o respaldo do poder público.

Apesar da má distribuição de renda, a industrialização que se afirmou a partir de 1930 e vai até o final da $2^{\mathrm{a}}$ Guerra Mundial representou, de um modo geral, a modernização da sociedade. A partir de 1940, o País passou a apresentar crescimento do PIB superior a $7 \%$ ao ano - índice que se manteve até a década de
80 -, o que contribui para o aumento da qualidade de vida, especialmente da população urbana em comparação com a população rural.

Com o final da $2^{a}$ Guerra Mundial, houve uma alteração do padrão de industrialização nacional que influiu novamente no processo de construção das cidades: se na década de 30 houve o deslocamento do centro dinâmico da economia nacional para a economia doméstica devido à crise econômica internacional da década de 1930, após a $2^{a}$ Guerra Mundial, porém, o centro de decisões não será mais interno ao País, e deixa de ter como seu epicentro o mercado nacional. Isto porque, a partir daí, o capital estrangeiro passou a financiar a instalação de setores tecnológicos mais avançados na indústria nacional, tomando impulso o desenvolvimento tecnológico dependente no Brasil.

Com a produção de bens de consumo duráveis e até mesmo bens de produção que empurraram o novo processo de industrialização, as migrações internas e a urbanização ganharam um ritmo acelerado. Na década de 50, "a vida na cidade atrai e fixa porque oferece melhores oportunidades e acena um futuro de progresso individual, mas, também, porque é considerada uma forma superior de existência" (SCHWARCZ, 1998, p.574). Assim, a produção de eletrodomésticos, bens eletrônicos e automóveis desembocam em transformações do modo de vida, da cultura, dos hábitos de consumo e, também, do processo de urbanização:

\section{Da ocupação do solo urbano até o interior da moradia, a transformação foi profunda [...] os bens modernos passam a integrar um cenário em que a pré-moder- nidade sempre foi muito marcante, especialmente na moradia ou no padrão de urbanização dos bairros e da periferia (MARICATO, 2000, p. 22).}

A instalação da nova indústria fordista, porém, em função dos baixos salários pagos aos trabalhadores, fez com que a favela fosse a única opção de habitação. É a figura do "produtivo excluído", que, mesmo inserido no mercado de trabalho, não possuía condições plenas para a própria reprodução (MARICATO, 
2003, p. 153). Além do "produtivo excluído", em que há alta taxa de exploração do trabalho, esse processo de industrialização dependente também foi responsável por um alto índice de desemprego, que também impulsionará o processo de construção da periferia (CARLOS, 2009, p. 305).

No ano de 1964, com a imposição do regime autoritário, há uma nova mudança de direção, desta vez com a alteração do modelo econômico, social e político de desenvolvimento, inclusive urbano. Isto porque, a partir do Regime Militar,

\begin{abstract}
As cidades brasileiras passam a ocupar o centro de uma política destinada a mudar seu padrão de produção. A drenagem de recursos financeiros pelo mercado habitacional, em escala nunca vista no País, ocasiona a mudança no perfil das grandes cidades, com a verticalização promovida pelos edifícios de apartamento (MARICATO, 2000, p. 23).
\end{abstract}

Essa verticalização das cidades, que se consolidou por meio de uma explosão imobiliária, foi viabilizada especialmente pela criação do Sistema Financeiro da Habitação (SFH), que, além de ser responsável pelas obras de saneamento da cidade, direcionou recursos financeiros para o mercado habitacional. Porém, uma vez que o financiamento imobiliário se dirigiu para as classes médias e altas, não contribuiu para que houvesse uma melhoria na qualidade da moradia da população de baixa renda.

Além disto, o conceito de zoneamento urbano adotado à época pela legislação urbanística no município de São Paulo conferiu tratamento homogêneo à população no tocante à moradia, sem considerar as desigualdades de renda ao determinar, por exemplo, exigências relativas à infraestrutura. Isto só fez aumentar a "cidade informal" que já vinha sendo construída desde o início da industrialização. Assim, "mais do que difusores de padrões de qualidade urbana e ambiental, como pretendia o legislador, estes instrumentos (legais) contribuíram para a escalada da ilegalidade urbana" (GROSTEIN, 2001, p. 13).
Para piorar o quadro, o mercado imobiliário do período foi acompanhado por atividades especulativas, e a valorização dos vazios urbanos fez com que a população de baixa renda fosse ainda mais relegada à região periférica da cidade:

\begin{abstract}
Verificam-se, nas metrópoles, um agravamento das condições de moradia das populações pobres - um processo de "periferização" do crescimento metropolitano, acompanhado de um aumento significativo nos índices de favelização - e um grau devastador de degradação ambiental provocado por loteamentos ilegais e ocupações sobre áreas protegidas e solos frágeis (GROSTEIN, 2001, p. 13).
\end{abstract}

Para ilustrar esse processo de periferização da metrópole de São Paulo no período, vale a pena citar que dos 67 barracos existentes em 1972 na região da Administração Regional da Sé, restaram, em 1979, apenas 13 (PASTERNAK, p. 2008, p. 115). Todas as favelas da zona central paulistana sofreram expulsão para a periferia ou se caracterizam pela estagnação do número de barracos. A partir daí, na década de 1970-80 se observa um aumento da população favelada de quase $35 \%$ ao ano.

Somente no início dos anos 80, o poder público da cidade de São Paulo passou a interferir em benefício da população moradora das favelas e assentamentos ilegais/irregulares, ao formular e institucionalizar uma política de regularização em massa de loteamentos e, ainda, investindo em programas como o Programa Pró-Luz, que ligou a energia elétrica nas regiões de favela e o Programa Pró-Água, que institui o abastecimento domiciliar de água, ou seja, programas direcionados a dar condições mínimas de sobrevivência para essa população. E isto ocorreu porque, conforme aponta Pasternak,

O poder público percebeu que a favela "veio para ficar”, em razão do crescente número de barracões e invasões, e interfere de outra maneira, não mais insistindo nas remoções e alojamentos provisórios, e sim procurando garantir condições mínimas de salubridade para os assentamentos existentes (PASTERNAK, 2008, p. 118). 
Vale ressaltar que essa promoção de políticas públicas se associa com uma tolerância do Estado à ocupação irregular. Com o aumento da população favelada, "a lógica concentradora da gestão pública urbana não admite a incorporação ao orçamento público da imensa massa, moradora da cidade ilegal, demandatária dos serviços públicos" (MARICATO, 2003, p. 157). Soma-se a isto, ainda, o alto custo de remoção dessa população, que, na maioria dos casos, ocupam terrenos públicos localizados na periferia e áreas de proteção ambiental. Conforme Maricato, a ocupação ocorre predominantemente nessas áreas porque,

\begin{abstract}
Quando a localização de uma terra ocupada por favelas é valorizada pelo mercado imobiliário, a lei se impõe. Lei de mercado, e não norma jurídica, determina o cumprimento da lei. Não é por outra razão que as áreas ambientalmente frágeis, objeto de legislação preservacionista, "sobram" para o assentamento residencial da população pobre. Nessas localizações, a lei impede a ocupação imobiliária: margens dos córregos, áreas de mangues, áreas de proteção ambiental, reservas. Mesmo quando se trata de áreas públicas, priorizadas nos assentamentos de favelas, sua proteção contra a ocupação depende de sua localização em relação aos bairros onde atua o mercado imobiliário, legal, privado. As áreas públicas ocupadas estão localizadas, geralmente, nas periferias esquecidas (MARICATO, 2003, p. 119).
\end{abstract}

0 que se verifica, portanto, é uma maior atenção pelo Estado ao patrimônio fundiário privado do que ao patrimônio público, o que é visível pela tolerância que há na ocupação ilegal quando não interferem em circuitos centrais da realização do lucro mobiliário privado. Caso a ocupação ocorra em propriedade privada, a lei se impõe categoricamente, o que se observa até os dias de hoje².

Com o processo de redemocratização do País, novas transformações no cenário econômico vêm à tona, o que produzirá, também, alterações na configuração socioespacial. Com o alto grau de endividamento pú-

2 É paradigmático o caso do Pinheirinho, em que milhares de pessoas foram desalojadas, em 2012, de um terreno particular ocupado em São José dos Campos - SP. blico herdado do período militar ${ }^{3}$ e a crise fiscal sem precedentes, o País entra em um período de recessão econômica na década de 80 que se estende por toda a década de 90 e que será responsável, entre outros problemas, por um agravamento das questões urbanas. É a partir dos anos 80 que se observa, pela primeira vez na história brasileira, uma grande concentração de pobreza no espaço urbano e o início da violência urbana no Brasil (MARICATO, 2000, p. 23).

Este período de crise econômica foi seguido por uma ascensão neoliberal, que, entre outros motivos, ocorreu devido à grande interferência de organismos internacionais tal como o Banco Mundial e o Fundo Monetário Nacional - no País, consentida pelo governo brasileiro a fim de se obter a renegociação da dívida pública. Assim, em face dessa interferência externa, o País vivenciou, especialmente na década de 90 , além de privatizações, a desregulamentação em diversos setores da economia, responsável por retirar entraves à entrada do capital estrangeiro e permitindo a sua valorização em solo brasileiro.

Vale destacar que o capital que caracteriza este período, que se estende até os dias de hoje, é um capital financeiro, volátil, característico da "era da globalização" e que vai transformar, também, a dinâmica de construção das cidades: a produção do espaço passa a ser parte de valorização do capital, e transforma as cidades construindo, destruindo e reconstruindo o espaço. Isto ocorre porque, nesta atual fase do sistema econômico, o capital que já não pode mais se fixar integralmente para se valorizar, devido a sua necessidade de expansão (CARLOS, 2009, p. 303; VALENÇA, 2008, p. 244-245) ${ }^{4}$. Assim, por meio do capital que busca se valorizar por meio da constru-

3 Vale lembrar que governo brasileiro encampou a dívida do setor privado, que, devido ao alto grau de endividamento com bancos estrangeiros, estava prestes a quebrar após a crise mundial do petróleo, da década de 70 , em face da elevação da taxa de juros.

4 Citando David Harvey, Valença explica, acerca da mobilidade do capital, que uma grande quantidade de capital fixo em um dado lugar mina a capacidade de realização deste capital por uma resolução espacial em outro lugar (VALENÇA, 2008, p. 245). 
ção do espaço, há um movimento de transformação das cidades, que toma corpo especialmente nas grandes metrópoles, conectadas ao circuito mundial.

Neste período neoliberal, São Paulo passou a experimentar um processo de desconcentração produtiva - ou seja, um movimento de migração para outros locais dos estabelecimentos industriais -, com a permanência das sedes do setor industrial na região metropolitana - motivo pelo qual não se pode falar, aqui, do fenômeno de desindustrialização. Isto fez com que o capital continuasse concentrado na metrópole paulistana, que passou a ter espaços livres para especulação imobiliária antes ocupados pelo setor industrial.

Assim, se antes a aplicação do dinheiro ocorria no setor produtivo, nesta conjuntura as aplicações financeiras passam a se concentrar no setor imobiliário associado ao conjunto de indústrias voltadas à construção civil (CARLOS, 2009, p. 303-310). Em face disto, ocorrem transformações do espaço urbano que vão além das antigas áreas industriais:

Numa metrópole superedificada como São Paulo, as mudanças que levarão à construção do eixo empresarial-comercial não se limitarão apenas às antigas áreas industriais, mas chegará às áreas residenciais, cabendo ao Estado decretar a "área como aquela de uso público", o que permitirá o processo de desapropriação, expulsando a população que aí mora (CARLOS, 2009, p. 303-310).

E o que explica a atuação do poder público em benefício deste processo, inclusive do direcionamento dos investimentos públicos para a construção de infraestrutura que atenda ao setor mobiliário, é que as verbas públicas são preferencialmente destinadas aos "lugares capazes de viabilizar a reprodução do capital de modo a fortalecer o papel econômico da metrópole de São Paulo na rede mundial das cidades" (CARLOS, 2009, p. 303-310)5.

5 Vale lembrar que o Estado, conforme explica Mascaro, corrobora para a dinâmica de valorização do valor para a própria sustentação, uma vez que é parte estrutural e necessária da própria reprodução capitalista (Mascaro, 2013, p. 17-50).
Ocorre ainda que, com o avanço da construção de novos edifícios, além da expulsão da população das áreas diretamente desapropriadas, se verifica uma valorização do espaço urbano que provoca demais alterações, como o deslocamento da população que paga aluguel; a venda de casas para a construção de edifícios e, ainda, a expulsão da favela para limites periféricos ainda mais distantes.

Essas transformações serão responsáveis pela mudança do perfil de moradores da região periférica, historicamente reservada à população de baixa renda. Isto porque passam a ser construídos condomínios de luxo direcionados à classe média com a promessa de "qualidade de vida", proximidade com a natureza, segurança, etc. -, que significam, na realidade, estratégia de marketing do mercado em face da escassez de terrenos na metrópole superedificada (CARLOS, 2009, p. 303-310).

Com a diversificação dos grupos sociais nessas regiões, a atuação estatal passa a ser diferente nestes espaços, com o investimento em infraestrutura e serviços públicos. Apesar disto, a população de baixa renda não se beneficia desta infraestrutura, uma vez que valoriza o espaço e desloca a população de baixa renda para regiões ainda não valorizadas e mais periféricas, ainda que muito próximas dos novos condomínios de luxo (CARLOS, 2009, p. 303-310). Além do mais, a construção destes condomínios "tende a produzir enclaves sem quase nenhum contato entre os grupos sociais", permanecendo, portanto, a segregação classial (TORRES et al, 2003, p. 98).

Não só as regiões periféricas, mas também outros espaços da metrópole sofreram modificações: populações pobres vão se instalar em pequenos espaços não ocupados da cidade, tal como em baixo de viadutos, espaços entre pontes e margens de rios, linhas férreas, etc (TORRES et al, 2003, p. 98). Assim, verifica-se que as regiões ocupadas informalmente sempre são aquelas que se mostram desvalorizadas no mercado imobiliário. 
Com isto, "a situação de baixa renda define, por si mesma, as possibilidades de localização no tecido urbano" (BÓGUS, 1991, p. 47). Ou seja, é a renda auferida que vai determinar a maneira que se dá a ocupação da cidade, tanto a formal como a informal.
E é este o cenário que permanece na metrópole até os dias de hoje. A seguir, veremos de que maneira a concessão ou regularização da propriedade é capaz de solucionar o problema da moradia da população de baixa renda.

\section{A REGULARIZAÇ̃̃O DA PROPRIEDADE COMO SOLUÇÃO PARA A QUESTÃO DA MORADIA}

Conforme visto, a questão da moradia informal e irregular é um problema que se estende no desenvolvimento de São Paulo desde a década de 1930, momento em que a industrialização se acelerou e impulsionou a construção da cidade. Agora resta compreender se a regularização ou concessão de propriedade para os moradores desta cidade informal é capaz de solucionar a questão da precariedade na moradia.

Maricato aponta que a urbanização e legalização da cidade informal conferem melhor qualidade e status de cidadania a seus moradores. Isto porque a regularização jurídica possibilita mais estabilidade e segurança jurídica, o que interfere nas chances dessa população de obter emprego, crédito, etc, ou seja, na sua condição de cidadão (MARICATO, 2003, p. 163). No mesmo sentido, aponta Santos: em estudo realizado em uma favela na cidade do Rio de Janeiro, que ele preferiu atribuir o nome fictício de Pasárgada, percebeu-se que o medo dos moradores chamarem a atenção para a questão de sua ilegalidade faz com que não procurem a justiça, "como se a legalidade da posse de terra repercutisse sobre todas as outras relações sociais, mesmo sobre aquelas que nada tem com a terra ou com a habitação" (SANTOS, p. 8).

Para além da questão da cidadania, De Soto aponta que a regularização da propriedade, ao permitir mais segurança ao morador, faz com que este passe a investir na melhoria de sua residência, aquecen- do a economia e gerando, assim, um círculo vicioso. Para ele, tanto a favela como o comércio informal se tratam de "capital morto", sendo a questão central a transformação deste capital em "capital líquido", por meio da concessão formal do título de propriedade. Ou seja, é o título formal que permitiria a segurança e integração da população de baixa renda à economia. (FERNANDES, 2008, p. 26-27)

A proposta de De Soto já foi transformada em políticas públicas em diversos países e é aclamada por parte da doutrina especializada. Além do mais, o Banco Mundial passou a condicionar para liberação de recursos a elaboração pelos governos de propostas de legalização de propriedade (FERNANDES, 2008, p. 26-27). Apesar disto, a proposta de De Soto não dá conta de resolver a inclusão da população de baixa renda à economia, pelo contrário: a propriedade privada está na base do conflito de classes, sendo a expressão da acumulação do capital e da exploração da mão de obra. Assim, a concessão de propriedade privada só é capaz de fortalecer ainda mais o sistema de segregação socioespacial.

Conforme aponta Marcuse, "quanto mais os direitos de propriedade forem fortalecidos numa dada distribuição de poder qualquer, mais essa distribuição de poder será fortalecida”. Ou seja, quanto mais se fortalece o direito de propriedade em um cenário em que poucos são proprietários e muitos os despossuídos, 
mais se agrava o problema da exclusão. Até porque, assegurar mais propriedade em um cenário de desigualdade é atribuir mais poder aos que já são proprietários de terra para expulsar aqueles que a ocupam informalmente (MARCUSE, 2008, p. 12).

Ademais, conforme aponta Fernandes, a proposta de De Soto se trata de uma "indústria da legalização", e não de direito à moradia. Conforme o autor,

Há várias pesquisas indicando que, quando se tem um conjunto de fatores políticos, institucionais e sociais - por exemplo, a criação de Zeis (Zonas Especiais de Interesses Sociais), normas urbanísticas próprias, programas de gestão, enfim, uma série de medidas adequadas -, mesmo sem legalização, mesmo sem títulos, as pessoas se sentem seguras da sua posse o suficiente para investirem nas suas casas e nos seus negócios continuamente. Nos assentamentos consolidados, muitos obtêm crédito informal mesmo sem legalização e, em muitos casos, obtêm até crédito formal (FERNANDES, 2008, p. 27).

Ou seja, a segurança do morador não se relaciona necessariamente a um título formal de propriedade, mas a um conjunto de fatores que estabeleça essa segurança. Ademais, a simples concessão de propriedade não modifica a condição financeira da população de baixa renda, o que faz com que, em muitos casos, as taxas e tributos advindos com essa concessão culminem em um efeito reverso: o morador, sem condições de arcar com essas obrigações, vende a propriedade e vai ocupar outras áreas:

A propriedade, sob um amplo sistema de leis, carrega consigo obrigações formais, obrigações que os pobres quase nunca podem assumir. Isso pode incluir o pagamento de impostos, taxas de serviços, aluguel, obrigação pela manutenção, subordinação às regulações ambientais e de construção (MARCUSE, 2008, p. 12).

No mesmo sentido, Fernandes aponta que, para além da concessão ou regularização do título de propriedade, “a legalização por si só, se não for pensada em um quadro mais amplo de obras de urbanização, políticas sociais, programas econômicos, mecanis- mos de gestão, acaba por provocar efeitos inesperados e mesmo perversos" (FERNANDES, 2008, p. 2728). É premente, portanto, uma série de medidas que ultrapassam a concessão do título de propriedade ou, até, que a desconsidere. Até porque, propriedade privada e o direito a uma moradia digna não são necessariamente coincidentes (FERNANDES, 2008, p. 27-28).

Para Marcuse, é válido se desconsiderar os direitos plenos de propriedade para se pensar quais direitos são capazes de produzir moradia aos despossuídos. Assim, outras medidas seriam possíveis que não a concessão do título de propriedade, tal como o "direito à ocupação, sem incômodos, por toda a vida”, aliado com algumas poucas obrigações, como "pagar por serviços correntes no limite do poder de compra da renda do ocupante". Para o autor, ainda, a compreensão do direito à moradia deve estar aliada ao direito de uso, e não ao direito à propriedade privada (MARCUSE, 2008, p. 12-17).

A questão de fundo, porém, é saber como é possível estabelecer um "direito à ocupação permanente, sem incômodos" em um sistema político e econômico baseado na troca e que se fundamenta em um direito natural à propriedade privada. Ainda mais nesta atual fase, em que, conforme visto, a própria construção, destruição e reconstrução do espaço se tornaram meio de valorização do capital.

Ademais, uma vez que o próprio direito de uso do solo tem seu valor no mercado - tendo em vista que no atual sistema, tudo e todos são considerados mercadorias -, esta medida não é capaz de solucionar a segregação socioespacial da população de baixa renda, já que as possibilidades de localização habitacional da população estão diretamente relacionadas com o valor do solo urbano e a renda familiar auferida (BÓGUS, 1001, p. 47). Assim, a população pobre continuaria relegada a habitações informais, localizadas em regiões menos valorizadas e sem infraestrutura. 


\section{CONCLUSÃO}

Ao analisar os processos constitutivos da formação do espaço urbano na região metropolitana de São Paulo e a formação da moradia ilegal e irregular nessa região, foi possível perceber que:

I - o processo de construção da cidade é determinado predominantemente pelo poder econômico e, assim, conformado pelas alterações do cenário econômico. Conforme visto, no início do século XX, em que a industrialização ainda se mostrava incipiente, a cidade paulistana foi ocupada por vilas operárias em sua região central, com vistas a garantir tendo em vista possibilitar a moradia do operariado, também escasso em um país predominantemente rural. Com o surgimento de uma mão-de-obra excedente devido à dinamização do setor industrial na década de 1930, houve uma precarização das condições de moradia que culminou, além do surgimento de cortiços e favelas, na ocupação da periferia da cidade e no surgimento da “cidade ilegal". Na década de 1950 há uma aceleração do processo de urbanização, novamente relacionada a uma transformação do setor econômico: o País passa a produzir bens de consumos duráveis e de produção em um processo de industrialização dependente tecnologicamente. Aqui, seja pelo fator desemprego provocado por este processo, ou pelos baixos salários pagos pelo setor industrial, as favelas ou habitações precárias se constituem como única possibilidade de moradia para os desempregados e "produtivos excluídos". A explosão imobiliária no período militar, acompanhada por atividades especulativas, modifica a cara da cidade, verticalizando-a, ao mesmo tempo em que expulsa para regiões ainda mais periféricas a população de baixa renda. Já após a redemocratização do País, com a ascensão neoliberal e entrada desenfreada do capital financeiro, a metrópole passa por um processo de desconcentração produtiva, e a produção do espaço passa a ser parte da valorização do capital. Com a valorização do espaço urbano, a classe média também passa a ser deslocada para os limites periféricos, o que a deixa lado a lado com a população de baixa renda, embora em universos distintos de possibilidades. Ou seja, é a conjuntura econômica que vai moldar o cenário da metrópole de São Paulo.

II - o poder público contribui por vezes com o processo de segregação socioespacial e precariedade no setor da habitação, uma vez que sua lógica de atuação é voltada para o próprio fortalecimento econômico da metrópole. Isto se verifica pelo direcionamento dos investimentos públicos na construção de infraestrutura que atenda ao setor imobiliário, na remoção de habitações precárias ou até desapropriações de regiões que se valorizam e até mesmo por meio de sua legislação urbanística, quando trata indistintamente com exigências ou tributos populações economicamente desiguais. Vale lembrar, ainda, da omissão estatal em relação às ocupações irregulares quando a remoção demanda alto custo, isto é, quando se tratam de terrenos públicos ou de áreas de preservação ambiental, desvalorizados pelo mercado imobiliário.

III - é a condição de renda da população que define as possibilidades de moradia, tanto da cidade legal como ilegal. Assim, a população pobre - tanto os desempregados como de produtivos excluídos -, não possui opção de habitação que não cortiços, casas autoconstruídas ou favelas. Ademais, a condição de legalidade dessas habitações, uma vez que está atrelada a uma série de obrigações - a titularidade da propriedade ou o pagamento de aluguel, pagamento de tributos, etc. -, também se define pela renda. Vale apontar ainda que é a renda que vai determinar a localização dessas habitações: nunca em regiões valorizadas pelo mercado imobiliário, sob pena de remoção.

Na segunda etapa deste estudo se promoveu um exame do debate acerca da regularização da proprie- 
dade como solução para a questão da moradia precária, podendo se observar que:

I - o título de propriedade pode assegurar maior segurança ao morador da cidade ilegal, já que interfere em sua relação com o meio e sua condição de cidadão: seja por maiores possibilidades de se obter um emprego, de se conseguir crédito e, até, de usufruir dos serviços públicos, uma vez que não haverá mais receio para se chamar a atenção para a situação de ilegalidade.

II - um conjunto de fatores políticos e sociais, que não a concessão do título de propriedade, também pode dar segurança ao morador, tal como o estabelecimento de Zonas Especiais de Interesse Social. Assim, o título de propriedade não é um requisito indispensável para se conceder segurança a um morador de habitação ilegal se houver uma conjuntura que propicie essa segurança.

III - a mera concessão do título de propriedade não é suficiente para a melhoria das condições de habitação do morador de baixa renda, uma vez que carrega consigo obrigações legais que a população pobre não tem condições de assumir.

IV - o reforço do direito à propriedade privada pode carregar consigo um efeito perverso em uma sociedade em que a distribuição de renda é desigual, uma vez que pode significar o reforço do poder aos que tem propriedade em detrimento dos despossuídos, que estariam ainda mais vulneráveis a remoções.

Feitas essas considerações, é possível constatar, enfim, que a simples regularização da propriedade não dá conta de solucionar a precariedade na questão da habitação. E isto porque, conforme visto, além da concessão/regularização da propriedade ou o fortalecimento deste direito ser insuficiente e carregar consigo efeitos perversos, o processo de formação da cidade ilegal encontra raízes no próprio desenvolvimento econômico, determinante na construção da cidade. Assim, sanar a questão da moradia para a população de baixa renda significa, antes, sanar as desigualdades engendradas pelo sistema, e não a concessão de mais propriedade.

\section{REFERÊNCIAS}

BÓGUS, Lúcia Maria Machado. Direito à Cidade e Segregação Espacial. São Paulo em Perspectiva, nº 5, 1991 , p. 47-50.

DOURADO, Sheilla Borges. A ilegalidade urbana e o meio ambiente. In: FERNANDES, Edésio; ALFONSIN, Betânia (orgs.). A lei e a ilegalidade na produção do espaço urbano. Belo Horizonte: Del Rey, 2003.

FERNANDES, Edésio. Cidade legal x ilegal. In: VALENÇA, Márcio Moraes (org.). Cidade (i)legal. Rio de Janeiro: Mauad X, 2008.

GROSTEIN, Marta Dora. Metrópole e expansão urbana: a persistência de processos “insustentáveis”. São Paulo em Perspectiva, $n^{\circ} 15,2001$. p. 13-19 
MARCUSE, Peter. $O$ caso contra os direitos de propriedade. In: VALENÇA, Márcio Moraes (org.). Cidade (i)legal. Rio de Janeiro: Mauad X, 2008.

MARICATO, Ermínia. Urbanismo na periferia do mundo globalizado: metrópoles brasileiras. São Paulo em Perspectiva, $n^{0} 14,2000$. p. $21-33$

MARICATO, Ermínia. Metrópole, legislação e desigualdade. Estudos Avançados, nº 17, 2003. p. 151-165

MASCARO, Alysson Leandro. Estado e forma política. São Paulo: Boitempo, 2013.

PASTERNAK, Suzana. A cidade que virou favela. In: VALENÇA, Márcio Moraes (org.). Cidade (i)legal. Rio de Janeiro: Mauad X, 2008.

PAULANI, Leda Maria, "A Utopia da Nação: Esperança e Desalento" in PEREIRA, Luis Carlos Bresser \& REGO, José Márcio (orgs), A grande esperança em Celso Furtado: ensaio em homenagem aos seus 80 anos, São Paulo, Ed. 34, 2001, pp. 139-156.

SANTOS, Boaventura de Souza. Notas sobre a história jurídico-social de Pasárgada. Disponível em: http:// www.dhnet.org.br/direitos/militantes/boaventura/ boaventura_pasargada_passar.pdf. Acesso em: 30.07 .13

SCHWARCZ, Lilia Moritiz. Introdução. In: SCHWARCZ, Lilia Moritiz (org.). História da Vida Privada no Brasil. Companhia das Letras, 1998.

TORRES, Haroldo da Gama; MARQUES, Eduardo; FERREIRA, Maria Paula; BITAR, Sandra. Pobreza e espaço: padrões de segregação em São Paulo. Estudos Avançados, nº 17, 2003. p. 97-128

VILLAÇA, Flávio. A segregação urbana e a justiça (ou a justiça no injusto espaço urbano). In: MUSSI, Andréa Quadrado; GOMES, Daniela; FARIAS, Vanderlei de Oliveira Farias (orgs.). 0 Estatuto da Cidade - os desafios da cidade justa. Passo Fundo: IMED, 2011. p. 47-55 
